\title{
Effect of Instructional Program on Patients' Knowledge Regarding Adherence to Therapeutic Regimen of Type 2 Diabetes Mellitus
}

\section{Karema Abd El-Rhman Mohamed ${ }^{1}$, Prof. Nagat Said Habib ${ }^{2}$, Prof. Gehad Mohamed Abo El-maty ${ }^{3}$, Prof. Mamdouh Radwan El-Nahas ${ }^{4}$, Dr. Fatma El-emam Hafez ${ }^{5}$}

M.Sc. in Public Health Nursing, Faculty of Nursing, Benha University ${ }^{1}$; Professor of Community Health Nursing, Faculty of Nursing, Cairo University ${ }^{2}$; Professor of Family and Community Health Nursing, Faculty of Nursing, Port Said University ${ }^{3}$; Professor of Internal medicine, Faculty of Medicine, Port Said University ${ }^{4}$. Assistant professor of Family and Community Health Nursing, Faculty of Nursing, Port Said University ${ }^{5}$

\begin{abstract}
Background: Type 2 diabetes mellitus is considered a serious, an increasing global health burden, and leading cause of premature morbidity and worldwide mortality due to its complications. Aim: This study aimed to examining the effect of instructional program on knowledge regarding adherence to therapeutic regimen among type 2 diabetic patients. Subjects and method: Design: A quasi-experimental research design was utilized. Setting: This study was carried out at diabetic out-patient clinic in Medical Specialized Hospital affiliated to Mansoura University. Subjects: a sample of 53 participants who fulfilled the inclusion criteria of the study was selected. Tool: A structured interview which included four parts was used in carrying out this study. Results; $73.6 \%$ of the studied patients were females; and $79.2 \%$ had low socioeconomic level. Regarding the total score level of knowledge, $84.9 \%$ of the studied sample had satisfactory score level after applying the instructional program, $98.1 \%$ of them had satisfactory beliefs after applying the instructional program. And, 58.5\% of the sample had high score level of adherence after applying the instructional program. The mean $\pm \mathrm{SD}$ of glycosylated hemoglobin of the subjects was decreased significantly from $9.5 \pm 1.7$ to $7.9 \pm 1.2$ after applying the instructional program. Conclusion and Recommendations; improving diabetic patients' knowledge regarding type 2 diabetes mellitus was very important for improving adherence to the therapeutic regimen .Developing instructional plan based on issues related to diabetic regimen and personal perceptions that militate against adherence.
\end{abstract}

Key words: Adherence, Health Belief Model, Type 2 diabetes mellitus 


\section{INTRODUCTION}

Diabetes is a disorder of the pancreas in which the beta cells of the islets of Langerhans of the pancreas fail to produce an adequate amount of insulin, or use insulin appropriately, resulting in the body's inability to metabolize carbohydrates, fats, and proteins appropriately (Jones, 2016).

Type 2 diabetes mellitus (T2DM) was previously called non-insulin dependent diabetes mellitus, it may accounts for about $85 \%$ to $95 \%$ of all diagnosed cases of diabetes; it is resulted from a combination of resistance to the action of insulin, and insufficient insulin produced by the pancreas (Detels et al., 2015).

The exact cause of diabetes is unknown. A number of factors contribute to its development; genetic predisposition, the aging process, diet, lifestyle, and ethnicity. In fact, the obesity is believed to be a single most important clinical predictor of T2DM (Cooper and Gosnell, 2015). Worsens glucose tolerance, and smoking increase the diabetes risk. Moreover, a history of gestational diabetes and a family history of T2DM are all strong predictors of T2DM (Goldstein and Wieland, 2016).

Type 2 diabetic patients can often be managed by diet and weight reduction alone. If they do not respond adequately, oral hypoglycemic drugs are added. Many of this drugs act by promoting the release of insulin from pancreatic islets, and they are only useful for treating T2DM. If diet, weight reduction, and hypoglycemic drugs do not control the hyperglycemia, insulin is used to regulate blood glucose (Crowley, 2014).

Diabetes is a chronic condition with many complications, and its management would need sufficient levels of knowledge, self-care behaviors and adherence to medications. For effective management and in order to have a good glycemic control, patients need to have adequate levels of knowledge of diabetes regarding self-care, a concept that foster adherence to medications, good dietary pattern and physical activity (Kassahun et al., 2016).

Providers describe patients' lack of sufficient knowledge about the disease as one of the primary reasons underlying poor medication adherence. Providers consider discussions about medication-related issues, and improvement of patients' medication knowledge, important to promoting medication adherence (Brundisini et al., 2015). Community health nurse had worked to educate Patients to assume responsibility in their management of diabetes mellitus. In addition, community health nurses have been actively involved in 
education and screening programs for groups at high risk. Included in these groups are individuals who have a family history of diabetes, those who are obese and older adults (Nies and McEwen, 2014).

\section{Significance of the study:}

Worldwide 415 million people or $8.8 \%$ of people at the age of $20-79$ are estimated to have diabetes; it is expected to increase up to 642 million people by 2040. In 2015, one in every 11 adults has diabetes and it is expected that the number will be one in every 10 adults by 2040. In 2015, 5 million deaths in were calculated. Besides, $12 \%$ of global health expenditure is spent on diabetes (International Federation of Diabetes, 2015). Type 2 diabetes mellitus (T2DM) is a fasting-growing health problem in Egypt with a significant impact on morbidity, mortality, and health care resources. Currently, the prevalence of T2DM in Egypt is around 15.6\% of all adults aged from 20 to 79 (Hegazi et al., 2015).

\section{AIM OF THE STUDY:}

The aim of the current study was to examine the effect of the instructional program on knowledge regarding adherence to therapeutic regimen among type 2 diabetic patients.

\section{Research Hypothesis}

The mean post-test score regarding adherence to therapeutic regimen, knowledge among type 2 diabetic patients attending the instructional program will be significantly higher than their pre-test score.

\section{SUBJECTS AND METHOD:}

\section{Design}

The study was carried out using a quasi-experimental research design, with pre-post assessment.

\section{Setting}

The study was carried out at the outpatient clinic in Medical Specialized Hospital affiliated to Mansoura University.

\section{Subjects}

The subjects were chosen considering the inclusion criteria, and they were randomly selected.

\section{Inclusion criteria:}

1. Patients who were diagnosed as a type 2 diabetic patients. 
2. Both sexes of adults' subscribed with the age 20-60years.

3. Patients who agreed to participate in this study.

\section{Exclusion criteria:}

1. Physically or mentally handicapped patients.

2. Patients who had chronic complications

\section{Study Sample}

The sample size was calculated based on the result of a previous research, which was "measuring the rate of therapeutic adherence among out-patients T2DM in Egypt", which was applied by Shams \& Barakat (2010), through using the following equation:

$$
\begin{aligned}
& \mathrm{n}=\mathrm{D}\left[\mathrm{Z}_{\alpha}(2 \mathrm{P}(1-\mathrm{P}))^{1 / 2}+\mathrm{Z}_{\beta}\left(\mathrm{P}_{1}\left(1-\mathrm{P}_{1}\right)+\mathrm{P}_{2}\left(1-\mathrm{P}_{2}\right)\right)^{1 / 2}\right]^{2} /\left(\mathrm{P}_{2}-\mathrm{P}_{1}\right)^{2} \\
& \mathrm{p} 1=0.4 \\
& \mathrm{p} 2=0.7 \\
& \text { Assuming confidence } 95 \% \\
& \mathrm{Z} \alpha=1.96 \\
& \text { For a power } 80 \% \\
& \mathrm{Z} \beta=1.282
\end{aligned}
$$

Based on this equation, fifty-three patients participated in this study after excluding those who participated in the pilot study. Also, three patients had passed away during the study.

\section{Tools of data collection:}

Data were collected by using one tool

Tool I: Structured interviewing. It was developed by the researcher based on reviewing related literature and experts' opinions; It is written in a simple Arabic language, and consisted of four main parts to assess the following:

Part 1: Socio-demographic characteristics of the studied sample: It was assessed by using the Socio-economic Scale(SES) that was adopted from El-Gilany, El-Wehady, and ElWasify (2012), which included 7 domains covering (education \& occupation; Family; income; family size; family possessions; home sanitation; and health care domain), These 7 domains composed of (17) multiple choice questions. 
The total score was 84 , it was classified into four levels depending on the quartiles of the score calculated; very low $(<21)$, low $(21-<42)$, middle 42-<64), and high $(64-84)$ social economic levels.

Part 2: Medical health profile of the studied patients, it developed by the researcher which covered: a. Disease History such as duration of disease, discover the disease, family history and other associated disorders. And b. Disease Treatment: such as, following diabetic diet, physical activity, measuring blood glucose level, and medication used. This data obtained as the patient report.

Part 3: Knowledge Assessment Questionnaire: it was developed by the researcher to assess patients' knowledge regarding T2DM.

\section{Scoring system of patients' knowledge:}

For assessing patients' knowledge, each correct answer was scored as (1) and incorrect answer or did not know scored as (zero). The total score for all questions related to knowledge was categorized into two levels as following:

- Satisfactory: when the score was $\geq 60 \%$ of the total score.

- Unsatisfactory: when the score was $<60 \%$ of the total score.

Part 4: Adherence to therapeutic regimen which was assessed by the following scales (1). Morisky Medication Adherence Scale (MMAS-8). It was adopted from Morisky et al. (2008) to assess medications adherence among type 2 diabetic patients. This scale was consisted of (eight) items that addressed specific medication taking behavior and adherence. The first 7 items had the response (yes) or (no), while the 8th item had 5- points Likert response.

\section{Scoring system:}

Each response of (Yes) was scored as (zero) and response of (No) was scored as (1) except item 5, in which the score was reversed. For the 8th item, each response of (never /rarely) was scored as (1); each response of (once in a while) was scored as (0.75); each response of (sometimes) was scored as (0.5); each response of (usually) was scored as (0.25); and each response of (all the time) was scored as (0). The total score for patients' adherence to medication was categorized as the following:

- $8=$ high adherence

- $6<8=$ medium adherence

- $<6=$ low adherence 
2. Health Belief Model (HBM) Scale: It was adopted from Given et al. (1983) and was adapted by the researcher. This scale consisted of basic four dimensions which were perceived susceptibility, perceived severity, perceived benefits and perceived barriers. It encompassed 16 statements, 4 statements for each dimension. A three levels Likert scale was developed by the investigator to measure the perception of diabetic patient towards the therapeutic regimen adherence.

\section{Scoring System:}

Responses of the diabetic patients regarding HBM were classified into three levels; agree, uncertain, and disagree, in which was scored as the following: agree was scored as (two), uncertain was scored as (one), and disagree was scored as (zero). The total score of patients' perception was developed by the researcher as the following:

- Satisfactory if the score was $\geq 60 \%$ of the total score.

- Unsatisfactory if it was $<60 \%$ of the total score.

3. Blood test was done for the patients to measure the level of glycosylated hemoglobin (HbA1c) before and after the program.

\section{Tool Content Validity}

The tool of this study was developed by the researcher except socio-economic Scale, Morisky Medication Adherence Scale, and Health Belief Model Scale. It was tested for content validity through a jury of five experts in the community health nursing, medical-surgical nursing, community health medicine. The necessary modifications were done accordingly.

\section{Reliability:}

The reliability was assured by calculating the test of Cronbach's $\alpha$ co-efficient. Its value was $(0.75)$, which indicated high reliability.

\section{Pilot study:}

The pilot study was carried out on $10 \%$ of the study sample, which included 5 adults' subscribers with T2DM from the pre-mentioned setting. The pilot study was done to test the clarity, relevance, applicability, feasibility of the developed tool and to estimate the time needed for data collection. Those subjects who shared in the pilot study were excluded from the main study sample as a result of the necessary modifications done to the questionnaire sheet. 


\section{Administrative:}

Before conducting this study, an official letter was issued from the Dean of the Faculty of Nursing- Port Said University to the administrator of Medical Specialized Hospital affiliated to Mansoura University after explaining the aim of the study to obtain their approvals to conduct the study. After obtaining the approvals, the researcher started to communicate with the study subjects and took their oral consents to participate in the study after clear explanation of the study aim.

\section{Ethical Considerations:}

Explain the aim of the study to each participant to be familiar with the importance of his / her participation. All data collected from the studied subjects will be processed in a total Confidentiality

\section{Field Work:}

The current study was carried out through the following four phases: assessment, program development, implementation, and evaluation. Collection of data and implementation of the instruction program lasted over a period of 9 months, from the beginning of January 2016 until the end of September 2016. The researcher visited the pre-mentioned setting 6 days per week from 9 am to $1 \mathrm{pm}$. The subjects were selected randomly (every 2 nd patient who met the inclusion criteria) until the sample size was completed.

\section{Phase I: Assessment phase (Pre-test phase):}

After preparing the tool, the study sample was selected according to the inclusion criteria. This was followed by collecting baseline data. Pre-test questionnaire was filled by the researcher after an oral consent from each patient to study their existing level of knowledge, adherence, and beliefs. Each interview took 40-45 minutes to be filled from each patient. Data collection was performed during the waiting time, while the patients were waiting to receive their medication from the hospital's pharmacy. This phase lasted for a period of two months

\section{Phase II: Program Development:}

The researcher designed the instructional program according to the patients' needs under the guidance of the supervisors. A simple booklet was developed for type 2 diabetic patients. The booklet was written in a simple Arabic language with different colored images to facilitate patients' understanding and enhance retention of their acquired knowledge. The booklet covered all items related to diabetes (definition, types, risk factors, laboratory investigations, acute and chronic 
complications, management of $\mathrm{T} 2 \mathrm{DM}$ as diabetic diet, insulin injection, physical exercise, monitoring blood glucose level, and foot care). This phase lasted for one month.

\section{Phase III: Program Implementation:}

The instructional program designed for this study was carried out in the teaching room affiliated to the pre-mentioned setting. The researcher interviewed the patients individually or in groups (2-4) patients The program included three sessions presented to each patient; each session lasted for 60-90 minutes. It was applied through using different teaching and learning methods which included; interactive lecture, discussion, demonstration and re-demonstration, instruction media such as data show presentation and printed handout (booklet). The first session was applied after the doctor checked up and before the patient received his monthly medication from the hospital's pharmacy. The second session was applied in the second day after the patient did his required laboratory investigation that included the HbAlc. The third session was applied at the third day after the patient did the laboratory investigation (while patient come to the hospital to receive the result of investigation $(\mathrm{HbA1c})$. The researcher was in contact with the patients through the mobile to enhance them for adherence. Duration of the program implementation (sessions) was two months.

\section{Phase IV: Evaluation:}

The same questionnaire was introduced to the study sample, and laboratory investigation done of $\mathrm{HbA} 1 \mathrm{c}$ three months after the program implementation. The results were compared to the pre-test results to evaluate the effect of the instructional program on the patients' knowledge, beliefs, and adherence to therapeutic regimen.

\section{RESULTS:}

Table (1): shows distribution of the studied sample according to their socio demographic data. The mean age of the studied sample with type 2 diabetes mellitus (T2DM) was 48.50 \pm 8.21 years, their ages ranged between 29-60 years. Concerning education, 32.1\% of the subjects were illiterate, while $5.7 \%$ had university education.. Also, $79.2 \%$ of the studied sample was belonged to low socioeconomic level. Regarding smoking $15 \%$ of the subjects were current smokers.

Table (2): shows distribution of the studied sample according to their disease history. $69.8 \%$ of them discovered their diabetes by the signs and symptoms, $43.4 \%$ of the studied sample had diabetes for less than five years. $73.6 \%$ of the subjects had a positive family history of diabetes. 
Table (2) :continues displays distribution of the studied sample according to their diet, exercise, and measuring blood glucose level pre and post program. It revealed that, in pre-test 13.2 $\%$ of the studied sample follow the diabetic diet regularly, $11.3 \%$ of them performed exercise regularly with a highly statistical significant difference compared to the Post-test, $\mathrm{P}<0.001$. Moreover, in pre-test $41.5 \%$ were following blood sugar level at home regularly, there were highly statistical significant differences compared to the post-test, $\mathrm{P}<0.001$.

Table (3): shows distribution of the studied sample according to their total Mean \pm SD of their total knowledge. The total mean of the studied sample was 59.8 \pm 22.9 in pre-test. Meanwhile, in the post-test Mean \pm SD was 105.3 \pm 20.1 , there was a statistical significant difference between the pre and test in the subjects knowledge, where $\mathrm{P}<0.001$.

Table (4): shows distribution of the studied sample according to their adherence to medication Pre and post program implementation. It illustrated that the total mean score level of the studied sample regarding to their adherence to medication therapy was $5.3 \pm 2.0$ in the pre-test. While, it was $7.3 \pm 1.3$ in the post-test, there was a statistical significant difference after applying the instructional program, where $\mathrm{P}<0.001$.

Figure (1): shows distribution of the studied sample according to their total score level of their adherence to medication therapy. There were only $17 \%$ of the studied sample had high score level of adherence to their medication therapy in the pre-test. While, $58.5 \%$ of the subjects had high adherence to medication after implementing the instructional program, there was a highly statistical significant difference between the pre and the post-test, where $\mathrm{P}<0.001$.

Figure (2) shows distribution of the studied sample according to their beliefs. It was found that $98.1 \%$ of them had satisfactory beliefs in the post-test compared to the pre-test. There was a highly statistical significance difference between pre and post-test, while $\mathrm{P}<0.001$.

Table (5): shows distribution of the studied sample according to their total mean score level of glycosylated hemoglobin pre and post. The total Mean \pm SD of the studied sample's result of glycosylated hemoglobin was $9.5 \pm 1.7$ in the pre-test. Meanwhile, in the post-test it was $7.9 \pm 1.2$, there was a statistical significant difference in the total mean score level of glycosylated hemoglobin after applying the program, where $\mathrm{P}<0.001$.

Table (6): shows statistical correlation between the studied sample's total knowledge score and their total adherence score levels pre and post program. There was a positive correlation with statistical significant difference between the studied sample's total knowledge score levels and their total adherence score levels in the post-test, where $(\mathrm{p}<0.05)$. 
Table (1): Distribution of the Studied patients according to their Socio-demographic Characteristics $(n=53)$.

\begin{tabular}{|c|c|c|}
\hline Item & No. & $\%$ \\
\hline \begin{tabular}{ll}
\multicolumn{2}{l}{ Gender } \\
$\bullet \quad$ & Female \\
$\bullet$ & Male
\end{tabular} & $\begin{array}{l}39 \\
14\end{array}$ & $\begin{array}{l}73.6 \\
26.4\end{array}$ \\
\hline 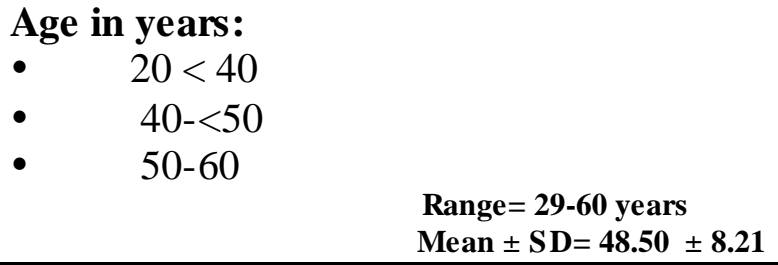 & $\begin{array}{l}10 \\
17 \\
26\end{array}$ & $\begin{array}{l}18.9 \\
32.1 \\
49.0\end{array}$ \\
\hline \begin{tabular}{ll}
\multicolumn{2}{l}{ Marital status } \\
$\bullet$ & Married \\
$\bullet$ & Widowed \\
$\bullet$ & Divorced
\end{tabular} & $\begin{array}{c}44 \\
6 \\
3\end{array}$ & $\begin{array}{c}83.0 \\
11.3 \\
5.7\end{array}$ \\
\hline \begin{tabular}{ll}
\multicolumn{2}{l}{ Educational Level } \\
- & Illiterate \\
- & Read/write \\
- & Basic education \\
- & Secondary \\
- & High education \\
\end{tabular} & $\begin{array}{c}17 \\
14 \\
7 \\
10 \\
5\end{array}$ & $\begin{array}{r}32.1 \\
26.4 \\
13.2 \\
18.9 \\
9.4 \\
\end{array}$ \\
\hline \begin{tabular}{ll}
\multicolumn{2}{l}{ Residence } \\
$\bullet$ & Rural \\
$\bullet$ & Urban \\
\end{tabular} & $\begin{array}{l}29 \\
24 \\
\end{array}$ & $\begin{array}{l}54.7 \\
45.3 \\
\end{array}$ \\
\hline \begin{tabular}{ll}
\multicolumn{2}{l}{ Occupation } \\
$-\quad$ & Not work \\
- & Working \\
\end{tabular} & $\begin{array}{l}35 \\
18 \\
\end{array}$ & $\begin{array}{l}66.1 \\
33.9 \\
\end{array}$ \\
\hline Current smoking & 8 & 15 \\
\hline 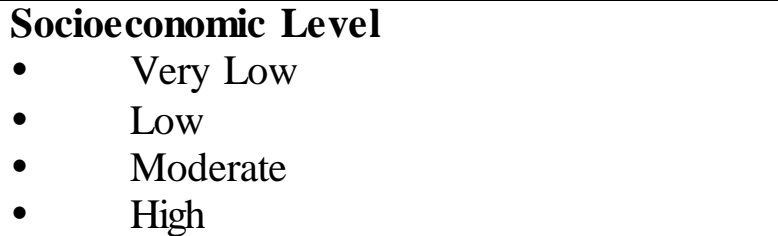 & $\begin{array}{c}1 \\
42 \\
7 \\
3\end{array}$ & $\begin{array}{c}1.9 \\
79.2 \\
13.2 \\
5.7\end{array}$ \\
\hline
\end{tabular}


Table (2): Distribution of the Studied patients According to their Disease History $(n=53)$

\begin{tabular}{|c|c|c|}
\hline Item & No. & $\%$ \\
\hline \multicolumn{3}{|l|}{ Duration of diabetes (in years) } \\
\hline$\bullet \quad<5$ & 23 & 43.4 \\
\hline - $\quad 5-<10$ & 15 & 28.3 \\
\hline $10-<15$ & 10 & 18.9 \\
\hline$\geq 15$ & 5 & 9.4 \\
\hline \multicolumn{3}{|l|}{ Diabetes discovered by } \\
\hline - $\quad$ Signs \& symptoms & 37 & 69.8 \\
\hline Routine examination & 8 & 15.1 \\
\hline Diabetic coma & 6 & 11.3 \\
\hline Other health problems & (24) & $(45.3)$ \\
\hline Hypertension & 23 & 43.4 \\
\hline Knee osteoarthritis & 11 & 20.8 \\
\hline - $\quad$ Fibromyalgia & 1 & 1.9 \\
\hline \multicolumn{3}{|l|}{ Family history of diabetes: } \\
\hline - $\quad$ Yes & 39 & 73.6 \\
\hline - $\quad$ No & 14 & 26.4 \\
\hline
\end{tabular}

* Answers were not mutually exclusive.

Table (2) continues: Distribution of the Studied patients According to their Disease Treatment (Diet, Exercise, and Measuring Blood Glucose Level ) Pre and Post Program ( $n=53)$.

\begin{tabular}{|c|c|c|c|c|c|c|}
\hline \multirow[t]{2}{*}{ Item } & \multicolumn{2}{|c|}{ Pretest } & \multicolumn{2}{|c|}{ Post test } & \multirow[t]{2}{*}{$\mathbf{X}^{2}$} & \multirow[t]{2}{*}{$\mathbf{P}$} \\
\hline & No & $\%$ & No & $\%$ & & \\
\hline Follow diet for diabetes regularly & & & & & & \\
\hline$\bullet \quad$ No & 31 & 58.5 & 2 & 3.8 & & \\
\hline - $\quad$ Yes & 7 & 13.2 & 37 & 69.8 & 45.974 & $<0.001^{* *}$ \\
\hline Sometimes & 15 & 28.3 & 14 & 26.4 & & \\
\hline Perform exercise regularly & & & & & & \\
\hline - $\quad$ No & 42 & 79.2 & 14 & 26.4 & & \\
\hline Yes & 6 & 11.3 & 23 & 43.4 & 29.727 & $<0.001^{* *}$ \\
\hline Sometimes & 5 & 9.5 & 16 & 30.2 & & \\
\hline Type of exercise & & & & & & \\
\hline Walking & 11 & 20.7 & 33 & 62.3 & 923 & 0.166 \\
\hline Running & 0.0 & 0.0 & 6 & 11.3 & & \\
\hline Follow blood sugar at home regularly & & & & & & \\
\hline - $\quad$ No & 4 & 7.5 & 2 & 3.8 & & $<0.001^{* *}$ \\
\hline - $\quad$ Yes & 22 & 41.5 & 41 & 77.3 & 14.208 & \\
\hline - $\quad$ Sometimes & 27 & 51.0 & 10 & 18.9 & & \\
\hline Rate of measuring blood sugar: & & & & & & \\
\hline - $\quad$ Once per day & 2 & 3.8 & 2 & 3.8 & & \\
\hline - $\quad$ Once per week & 0 & 0 & 4 & 7.5 & & \\
\hline - $\quad$ Twice per week & 1 & 1.9 & 10 & 18.9 & & $<0.001^{* *}$ \\
\hline Twice per month & 2 & 3.8 & 10 & 18.9 & & \\
\hline Once per month & 25 & 47.2 & 24 & 45.2 & 32.891 & \\
\hline When I feel tired & 19 & 35.8 & 1 & 1.9 & & \\
\hline
\end{tabular}

* Answers were not mutually exclusive.

Not Significant $P>0.05 \quad *$ Significant $P<0.05 \quad * *$ Highly Significant $P<0.001$. 
Table (3): Distribution of the Studied Sample According to their Total Mean Score of their Total Knowledge pre and post program $(n=53)$

\begin{tabular}{|c||r||r||c|c|}
\hline Item & Pre test & Post test & $X^{2}$ & $P$ \\
\hline \hline Total Mean \pm SD & $59.8 \pm 22.9$ & $105.3 \pm 20.1$ & 10.851 & $<0.0011^{* *}$ \\
\hline Not Significant P $>0.05$ & *Significant P<0.05 **Highly Significant P<0.001
\end{tabular}

Table (4): Distribution of the Studied Sample According to their Adherence to Medication Therapy $(\mathrm{n}=53)$.

\begin{tabular}{|c|c|c|c|c|c|c|c|c|c|c|}
\hline \multirow[t]{3}{*}{ Item } & \multicolumn{4}{|c|}{ Pre test } & \multicolumn{4}{|c|}{ Post test } & \multirow[t]{3}{*}{$\mathrm{X}^{2}$} & \multirow[t]{3}{*}{$\mathbf{P}$} \\
\hline & \multicolumn{2}{|c|}{ Yes } & \multicolumn{2}{|c|}{ No } & \multicolumn{2}{|c|}{ Yes } & \multicolumn{2}{|c|}{ No } & & \\
\hline & No & $\%$ & No & $\%$ & No & $\%$ & No & $\%$ & & \\
\hline $\begin{array}{l}\text { Do you sometimes forget to take your diabetic } \\
\text { medication? }\end{array}$ & 19 & 35.8 & 34 & 64.2 & 6 & 11.3 & 47 & 88.7 & 8.846 & $0.003^{*}$ \\
\hline $\begin{array}{l}\text { Over the past } 2 \text { weeks, were there any days when } \\
\text { you did not take yourdiabetic medications? }\end{array}$ & 30 & 56.6 & 23 & 43.4 & 7 & 13.2 & 46 & 86.8 & 21.964 & $<0.001^{* *} *$ \\
\hline $\begin{array}{l}\text { Have you stopped taking your medications without } \\
\text { telling your doctor, because you felt worse when you } \\
\text { took it? }\end{array}$ & 20 & 37.7 & 33 & 62.3 & 3 & 5.7 & 50 & 94.3 & 16.047 & $<0.001^{* * *}$ \\
\hline $\begin{array}{l}\text { When you travel or leave home, do you sometimes } \\
\text { forget to bring along your diabetic medications? }\end{array}$ & 16 & 30.2 & 37 & 69.8 & 1 & 1.9 & 52 & 98.1 & 15.763 & $<0.001 * *$ \\
\hline Did you take your diabetic medication yesterday? & 15 & 28.3 & 38 & 71.7 & 5 & 9.4 & 48 & 90.6 & 6.163 & $0.013^{*}$ \\
\hline $\begin{array}{l}\text { When you feel like your diabetes is under control, do } \\
\text { you sometimes stop taking your medicine? }\end{array}$ & 14 & 26.4 & 39 & 73.6 & 6 & 11.3 & 47 & 88.7 & 3.944 & $0.047^{*}$ \\
\hline $\begin{array}{l}\text { Do you ever feel hassled about sticking to your } \\
\text { diabetes treatment plan? }\end{array}$ & 15 & 28.3 & 38 & 71.7 & 4 & 7.5 & 49 & 92.5 & 7.759 & 0.005 \\
\hline $\begin{array}{l}\text { How often do you have difficulty remembering to } \\
\text { take all your medications? ( Please circle the correct } \\
\text { number) } \\
\text { Never/Rarely. } \\
\text { Once in a while. } \\
\text { Sometimes. } \\
\text { Usually. }\end{array}$ & & $\begin{array}{l}26 \\
7 \\
15 \\
5\end{array}$ & & & & 0 & & $\begin{array}{l}1.7 \\
8.9 \\
.5 \\
.9\end{array}$ & 11.814 & $0.008^{*}$ \\
\hline $\begin{array}{l}\text { Total } \\
\text { Range } \\
\text { Mean } \pm \text { SD } \\
\end{array}$ & & & $\begin{array}{l}5-8 \\
2.0\end{array}$ & & & & & & $\begin{array}{r}\text { T test } \\
6.082 \\
\end{array}$ & $<0.001 * *$ \\
\hline
\end{tabular}




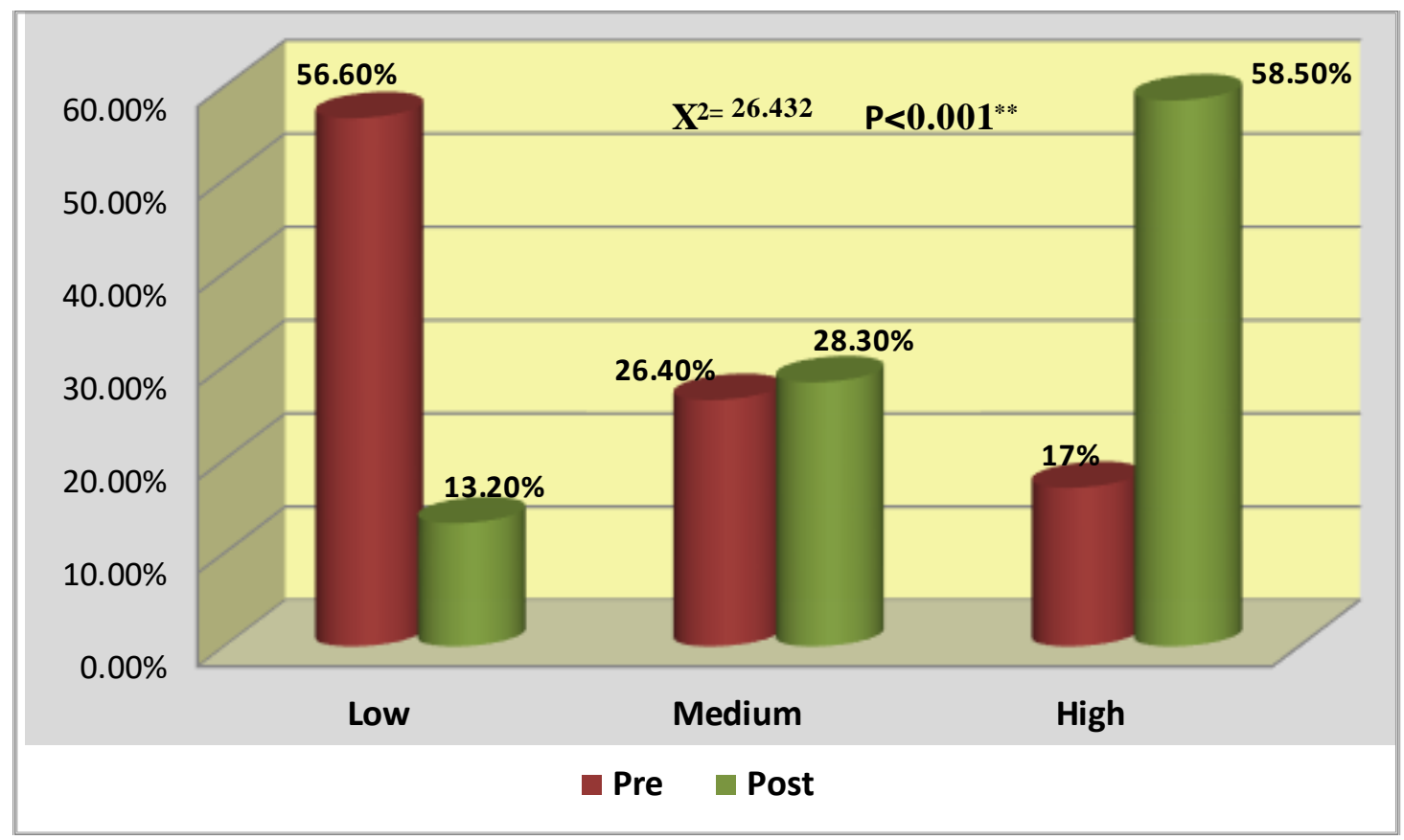

Figure (1): Distribution of the Studied Sample According to their Total Score Level of their Adherence to Medication Therapy $(n=53)$.

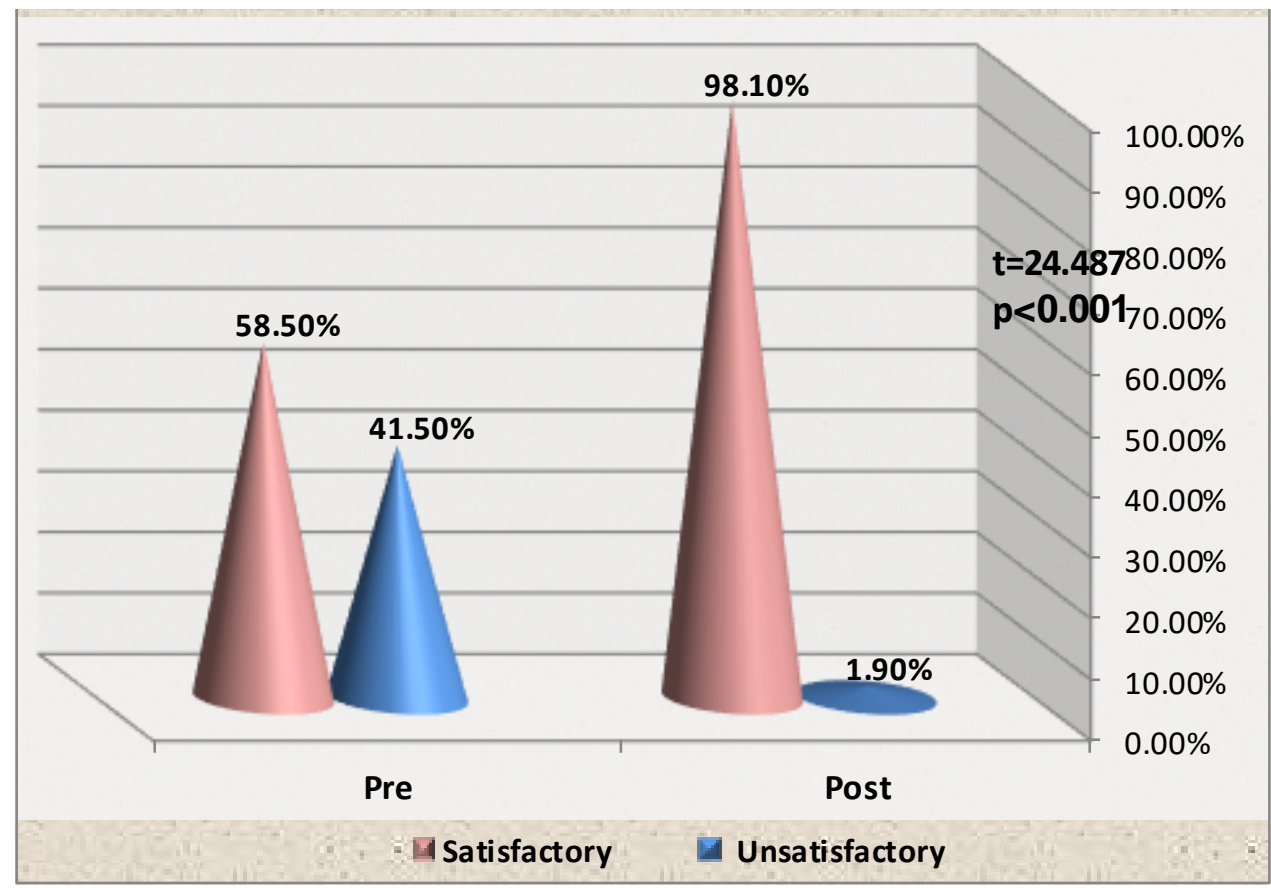

Figure (2): Distribution of the Studied Sample According to the Total Score Level Regarding to their Beliefs Related to their Therapeutic Regimen ( $\mathrm{n}=53$ ). 
Table (5): Distribution of the Studied Sample According to their Total Mean Score Level of Glycosylated Hemoglobin Pre and Post Program ( $n=53)$.

\begin{tabular}{|c|c|c|c|c|c|c|}
\hline \multirow[t]{2}{*}{ Glycosylated Hemoglobin } & \multicolumn{2}{|c|}{ Pre test } & \multicolumn{2}{|c|}{ Post test } & \multirow[t]{2}{*}{$\mathrm{X}^{2}$} & \multirow[t]{2}{*}{$\mathbf{P}$} \\
\hline & No & $\%$ & No & $\%$ & & \\
\hline $\begin{array}{l}\cdot \quad<6.5 \\
\cdot \quad \geq 6.5 \%\end{array}$ & $\begin{array}{c}2 \\
51\end{array}$ & $\begin{array}{c}3.8 \\
96.2\end{array}$ & $\begin{array}{c}7 \\
46\end{array}$ & $\begin{array}{l}13.2 \\
86.8\end{array}$ & 3.036 & 0.081 \\
\hline $\begin{array}{ll} & \text { Total } \\
\text { - } & \text { Range } \\
\text { - } & \text { Mean } \pm \text { SD }\end{array}$ & \multicolumn{2}{|c|}{$\begin{array}{c}6-14 \\
9.5 \pm 1.7\end{array}$} & \multicolumn{2}{|c|}{$\begin{array}{c}5-11 \\
7.9 \pm 1.2\end{array}$} & $\begin{array}{l}\mathrm{t} \text { test } \\
5.517\end{array}$ & $<0.001^{* *}$ \\
\hline
\end{tabular}

Not Significant P $>0.05 \quad *$ Significant P $<0.05 \quad * *$ Highly Significant $P<0.001$

Table (6): Statistical Correlation between the Studied Sample's Total Knowledge score and their Total Adherence Score Levels Pre and Post the Program ( $\mathrm{n}-=53)$

\begin{tabular}{||l|c|c|c||}
\hline \multicolumn{2}{|c|}{ Items } & \multicolumn{2}{c|}{ Total Knowledge Score Level } \\
\cline { 3 - 4 } & Pre-test & $\mathbf{0 . 1 5 1}$ & $\mathbf{0 . 2 8 2}$ \\
\hline \hline Total Adherence Score level: & Post-test & 0.282 & $0.041^{*}$ \\
\cline { 2 - 4 } & & & \\
\hline
\end{tabular}

Not Significant P $>0.05 \quad *$ Significant P $<0.05 \quad * *$ Highly Significant $P<0.001$

\section{DISCUSSION:}

The aim of the current study was to examine the effect of the instructional program on knowledge regarding adherence to therapeutic regimen among type 2 diabetic patients. It was observed that the minority of the studied sample reported that they were adherent to follow the diabetic diet, in the pre-test. This finding was improved to be more than two third of the studied sample after the application of the instructional program.

This finding was in accordance with Al-Hayek et al. (2013) who conduct a study "Impact of an Education Program on Patient Anxiety, Depression, Glycemic Control, and Adherence to Self-care and Medication in Type 2 Diabetes" in Saudi Arabia, and found that there was a significant improvement in following a certain diet between the pre and the posttest. This result reflected that, the subjects were eager to follow the instructions related to the diabetic diet; most of them were motivated and communicated with the researcher by phone.

On the other hand, there were less than one third of the subjects of this study who couldn't follow diabetic diet regularly, because they could not resist hunger detected as they 
report. The results revealed that the minority of the studied sample reported that they were performing exercise regularly in the pre-test. This finding was improved to be more than two fifth of the studied sample after implementation of the instructional program. This finding was slightly different but it went in the same line with Hassan (2012) who conducted a study "Effect of an Educational Program on Self Efficacy for Patients with Type 2 Diabetes Mellitus" in Benha city, and found that two fifth of the participants were performing exercise regularly in the pre-test and this finding was improved after implementing the program to be more than one third.

Concerning the studied sample's knowledge about diabetes and its regimen, the current study revealed that there were highly significant improvement between pre and posttest. In this regard, these results were in agreement with Taha, Zaton, Abd Elaziz (2016) who conducted a study "Impact of Health Educational Guidelines on the Knowledge, SelfManagement Practice and Self-efficacy of Patients with Type -2 Diabetes" in Zagazig, and mentioned that patients' knowledge about diabetes was generally low at the pre-guidelines phase, and the post-test showed significant improvements in all aspects of patient's knowledge about diabetes.

As shown in results, there was a highly statistically difference between pre and post test results in the total mean score level of the studied sample's knowledge about the diabetes and its regimen. the total mean score of all knowledge items of the studied sample was 59.8 \pm 22.9 before the instructional program that increased to $105.3 \pm 20.1$ after implementing the instructional program. This result was in the same line with Hassan (2012) found that the total knowledge score of the studied sample was $60.92 \pm 23.01$ before implementing the educational program, compared to $118 . \pm 15.41$ after implementing the educational program.

The findings clarified that only one fifth of the studied sample had a satisfactory knowledge score level before implementing the instructional program. After the implementation of the program, highly significant improvement in patients' knowledge score level was observed, where the majority of them had satisfactory knowledge score level. The pre-mentioned results strongly supported the hypothesis that the level of knowledge would be increased after the program implementation. This success of the program could be attributed to the process of education, interactions followed during its implementation and to the fact that it was custom tailored to patients' needs that always needed to be supported and motivated by the health care provider. This result was in the same line with Taha; Zaton; Abd Elaziz (2016) who found more than one fifth of the participants had a satisfactory score level of their knowledge at the pre-guidelines, reaching 100\% satisfactory at the post-test. 
Medication adherence was significantly improved after implementation of the instructional program. It was found that only less than one fifth of the subjects had a high score level in the pre-test. In the post-test, it was improved to be three fifths of them that had a high score level. These results were in the same line with Al-Haj Mohd et al., (2016) who conducted a study "Improving adherence to medication in adults with diabetes in the United Arab Emirates", and revealed that there was a significant increase in the adherence levels in the post stage of the intervention.

Regarding the total score levels of HBM, the results revealed that approximately two thirds of the studied sample had a satisfactory perception in the pre-test, which increased to be the majority after implementing the program. These findings support that the instructional program was effective in creating and improving paper perceptions regarding susceptibility, severity, benefits and barriers of the adherence to treatment. The success of the program could be attributed to improving patients' knowledge which affected their perceptions positively.

In relation to glycosylated hemoglobin (HBA1c), findings showed that the mean score level of HBA1c significantly decreased after application of the instructional program. This finding indicated that there was a significant improvement in controlling HBA1c among the subjects after application of the instructional program. This finding was in agreement with Zibaeenezhad et al. (2015) who carried out a study "The Effect of Educational Interventions on Glycemic Control in Patients with Type 2 Diabetes Mellitus", and found that the mean HBA1c was decreased significantly after the educational interventions compared to the pre educational interventions.

The results indicated that, improving patients' knowledge toward their disease and therapeutic regimen might positively affect their beliefs regarding therapeutic regimen which in turn improved their adherence. These findings were in agreement with Sweileh et al. (2014) who carried out a study "Influence of Patients' Disease Knowledge and Beliefs about Medicines on Medication Adherence: Findings from a Cross-Sectional Survey among Patients with Type 2 Diabetes Mellitus in Palestine", and mentioned that beliefs in one's medications and diabetes related knowledge were significantly associated with adherence.

\section{CONCLUSION:}

\section{Based on the present study findings, it can be concluded that:}

The minority of the studied sample were adherent to follow the diabetic diet and exercise. More than three quarters of them had unsatisfactory total knowledge score level. In 
addition, more than two quarters had unsatisfactory health beliefs relevant to adherence to the therapeutic regimen, and less than one fifth of the subjects had a high score level of medication adherence. After the implementation of the instructional program, there were significant improvements with highly statistical significant differences observed in the studied sample's adherence to follow the diabetic diet, performing exercise, and following blood sugar level after implementing instructional program. Also, there were significant improvements in the total score level of the studied sample regarding to their adherence to the medication, their knowledge and their health beliefs relevant to therapeutic regimen.

\section{RECOMMENDATIONS:}

Based on the results of the current study, the following recommendations were suggested:

- Providing continuous information on diabetic regimen to enhance its adherence.

- Developing instructional plan based on issues related to diabetic regimen and personal perceptions that militate against adherence.

- Further researches are needed with larger samples to better elucidate the effect for the intervention.

- Adding a long term follow-up component to the study that would provide an opportunity to test longitudinal effects.

\section{REFERENCES:}

Al-Haj Mohd, M.; Phung, H.; Sun, J.; and Morisky, D. (2016): Improving adherence to medication in adults with diabetes in the United Arab Emirates, BioMed Central Public Health, 16:857.

Al-Hayek, A.; Robert, A.; Al Dawish, M.; Zamzami, M.; Sam, A'; and Alzaid, A. (2013): Impact of an Education Program on Patient Anxiety, Depression, Glycemic Control, and Adherence to Self-care and Medication in Type 2 Diabetes, Journal of Family Community Medicine, 20(2):77-82.

Brundisini, F.; Vanstone, M.; Hulan, D.; DeJean, D.; and Giacomini, M. (2015): Type 2 Diabetes Patients' and Medication Nonadherence: A Qualitative Metasynthesis, BMC Health Services Research, 15:516.

Cooper, K.; and Gosnell, K. (2015): Foundations and Adults Health Nursing, 7th ed., Canada, Elsevier Mosby Comp., P1752,1768-1769. 
Crowley, L. (2014): Essentials of Human Disease, USA, Jones \& Bartlett Learning, P391.

El-Gilany, A.; El-Wehady, A.; and El-Wasify, M. (2012): Updating and Validation of the Socioeconomic Status Scale for Health Research in Egypt, Eastern Mediterranean Health Journal, 18(9):962-968.

Given, C.W.; Given, B. A.; Gallin, R. S.; and Condon, J. W. (1983): Development of Scales to Measure Beliefs of Diabetic Patients, Research in Nursing and Health Journal, (6): 127-141.

Goldstein, B. and Wieland, D. (2016): Type 2 Diabetes: Principles and Practice, 2nd ed., USA, CRC Press, Pp8,506.

Hassan, B. (2012): Effect of an Educational Program on Self Efficacy for Patients with Type 2 Diabetes Mellitus, Unpublished Doctorate Thesis, Faculty of Nursing, Benha University, Pp50.

Hegazi, R.; El-Gamal, M.; Abdel-Hady, N.; and Hamdy O. (2015): Epidemiology of and Risk Disease Knowledge Factors for Type 2 Diabetes in Egypt, Ann Glob Health, 81(6): 814-820.

International Federation of Diabetes, (2015): Diabetes in Egypt, available at: http://www.idf.org/membership/mena/egypt

Jones, B., (2016): Comprehensive medical terminology, 5th ed., USA, Cengage Learning Comp., p580.

Kassahun, T; Gesesew, H.; Mwanri, L.; and Eshetie, T. (2016): Diabetes Related Knowledge, Self-Care Behavior and Adherence to Medications among Diabetic Patients in Southwest Ethiopia: a Cross-Sectional Survey, BioMed Central Endocrine Disorder, 16 (28), Available at: https://www.ncbi.nlm.nih.gov/pmc/articles/PMC4933997/

Morisky, D.E.; Krousel-Wood, M.; Islam, T.; Webber, L.S.; Re, R.N.; and Muntner, P. (2009): New Medication adherence Scale Versus Pharmacy Fill Rates Seniors with Hypertension, The American Journal of Managed Care, 15(1):59-66.

Nies, M.; and McEwen, M. (2014): Community/Public Health: Promoting the Health of Populations, $6^{\text {th }}$ ed., USA, Elsevier Health Science, P323.

Shams, M.; and Barakat, E. (2010): Measuring the Rate of Therapeutic Adherence among Outpatients with T2DM in Egypt, Saudi Pharmaceutical Journal, 18 (4):225-232. 
Sweileh, W.; Zayoud, S.; Abu Nab'a, R.; Deleq, M.Enaia, M., Nassar, S.; and Al-jabi, S. (2014): Influence of Patients' Disease Knowledge and Beliefs about Medicines on Medication Adherence: Findings from a Cross-Sectional Survey among Patients with Type 2 Diabetes Mellitus in Palestine, BioMed Central Public Health Journal, 14 (94).

Taha, N.; Zaton, H.; and Abd Elaziz, N. (2016): Impact of Health Educational Guidelines on the Knowledge, Self-Management Practice and Self-efficacy of Patients with Type -2 Diabetes, Journal of Nursing Education and Practice, 6(9):46-55.

Zibaeenezhad, M.; Aghasadeghi, K.; Bagheri, F.; Khalesi, E.; zamirian, M. ; Moaref, A.; and Abtahi, F. (2015): The Effect of Educational Interventions on Glycemic Control in Patients with Type 2 Diabetes Mellitus, International Cardiovascular Research Journal, 9(1):17-21.

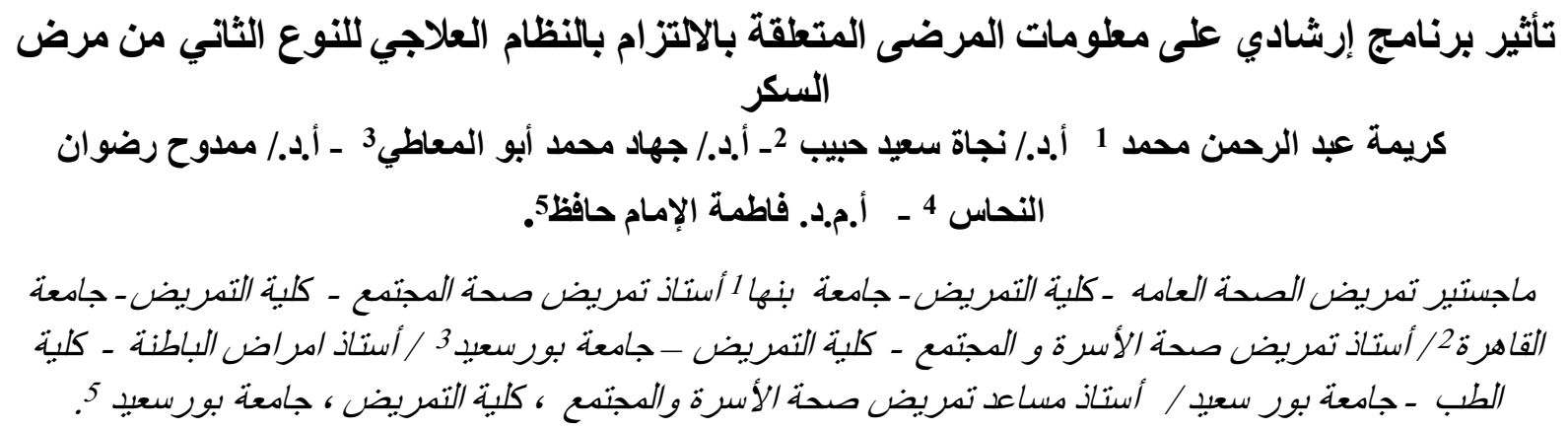

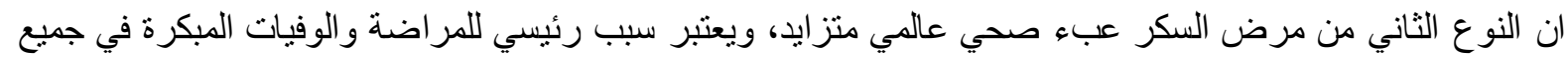

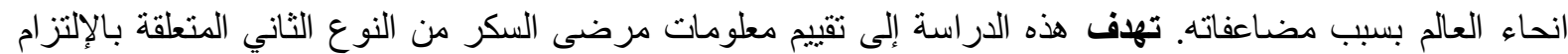

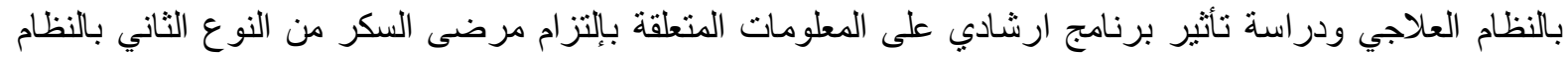

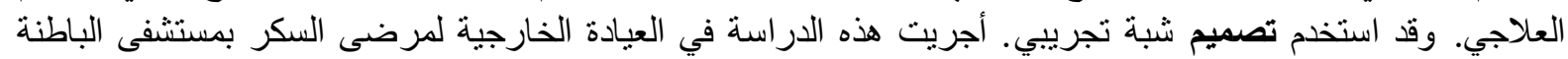
التخصصي التابعة لجامعة المذصورة. تم اختيار عينه عشوائيه مكونه من 53 مريض ممن استوفو معاير الدراسة. نم

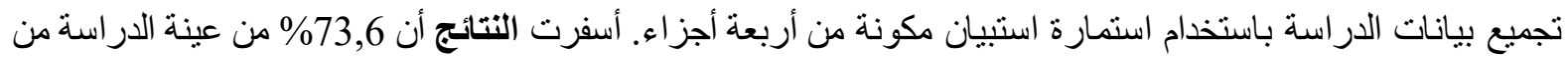

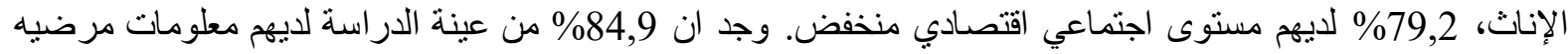

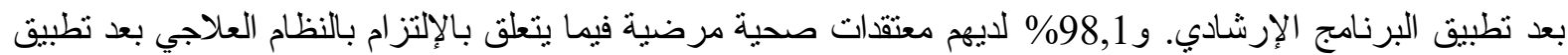

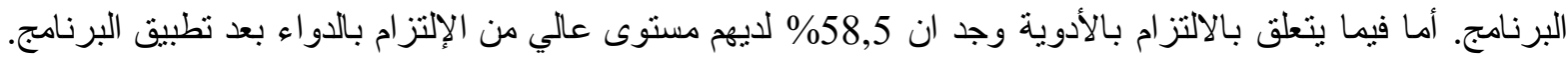

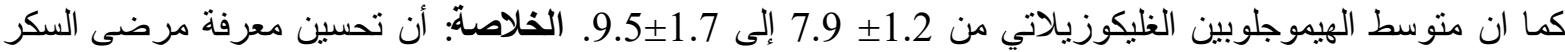

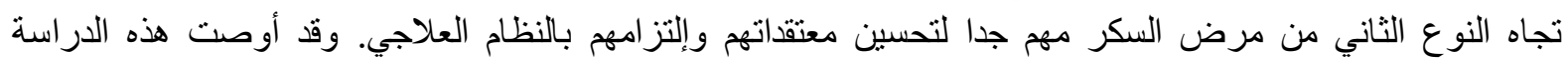

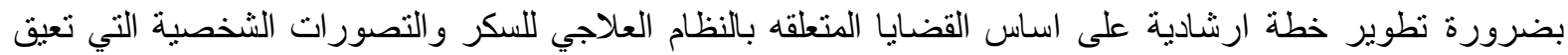

الكلمات المرشدة : النوع الثاني لمرض السكر ـ الإلنزام ـ نموذج المعتقد الصحي. 